\title{
CONVERSATIONALLY RELEVANT DESCRIPTIONS
}

\author{
Amichai Kronfeld \\ Natural Language Incorporated \\ 2910 Seventh St. \\ Berkeley, CA 94710
}

\section{Abstract}

Conversationally relevant descriptions are definite descriptions that are not merely tools for the identification of a referent, but are also crucial to the discourse in other respects. I analyze the uses of such descriptions in assertions as conveying a particular type of conversational implicatures. Such implicatures can be represented within the framework of possible world semantics. The analysis is extended to non-assertive illocutionary acts on the one hand, and to indefinite descriptions on the other.

\section{Introduction}

In an earlier paper [Kronfeld 1986], I have introduced the distinction between furctionally and conversationally relevant descriptions. All uses of definite descriptions for the purpose of referring are functional in the sense that they are supposed to identify the referent. But some uses of definite descriptions exhibit a type of relevance (or irrelevance) that goes beyond identification purposes. Consider the following example. As part of his effort to recruit more young people into the police force, the mayor of New York proclaims in a public speech:

1 New York needs more policemen.

Instead of "New York" he might have used “The Big Apple," or "The city by the Hudson," or some such description. It would not do, however, to say that

2 The city with the world's largest Jewish community needs more policemen

even though this description might be useful enough in identifying New York for the audience. It is simply irrelevant in this context. On the other hand, this same description might be quite relevant in a different context. For example, suppose the mayor were giving a speech at a reception in honor of Israel's Prime Minister. Under those circumstances, the atatement

3 The city with the world's largest Jewish community welcomes Israel's Prime Minister.

would make perfect sense. The difference, of course, is in the relevance of the description to the statement in (3), and its irrelevance to the one in (2). Uses of definite descriptions such as illustrated in example (3), are what I call conversationally relevant.

The distinction between functionally and conversationally relevant descriptions is part of a general model of referring that is based on what I have termed the descriptive approach to reference (Kronfeld 1990]. An ellucidation of the speech act of referring cannot be complete without understanding the role of conversationally relevant descriptions in the larger discourse. My hypothesis in [Kronfeld 1986] was that conversationally relevant descriptions function as part of implicatures of a particular type. The problem is to specify what this type is. An outline of a solution is the topic of the present paper.

\section{Implicature}

Why should we think that whenever a conversationally relevant description is used an implicature always exists? The reason for this has to do with the fact that discourse is something more than a simple sum of the isolated sentences that constitute its parts. Discourse consists of a sequence of utterances that are tied together in ways that make 
sense. Typically, there are reasons why a speaker says what he says in the order and manner that he says it, and in general a hearer must have a clue as to what these reasons are (this is why plan recognition is so important for plan-based theories of speech acts). Of course, the hearer cannot hope to know or even guess all of the reasons that led the speaker to participate in the discourse, but he can, indeed must, recognise some of them. As Allen, Cohen, Gross, Perranlt, and Sidner have pointed out (Allen 1978; Perrault and Cohen 1978; Allen and Perrault 1978; Allen and Perrault 1980; Gross and Sidner 1986; Sidner 1983; Sidner 1985], the recognition of what the speaker is "up to" contributes to coherence and comprehensibility of the discourse and is essential for the hearer's generation of an appropriate response.

Now, the unstated reasons whose recognition is required for discourse coherence are by definition implicated, since they must be inferred in order to preserve the assumption that the speaker is being cooperative. This is precisely what an implicature is. Moreover, turning to conversationally relevant descriptions, we should observe that by their very nature, they cannot be merely functionally relevant. That is, the assumption that they are intended mereily as tools for identification is not enough to make the discourse coherent. This, after all, is precisely what distinguishes functionally relevant descriptions from the conversationally relevant ones. Hence, additional assumptions are required in order to make sense of the way the speaker uses the latter descriptions. These assumptions themselves must be implicated.

Thus, in using a conversationally relevant description, the speaker implicates something. The content of implicatures that accompany such descriptions depends on circumstances, but they all share a rather specific form. My method in uncovering this form is this: taking the hearer's perspective, I begin by postulating that if the referring expression used by the speaker is merely functionally relevant, the speaker must be viewed as uncooperative. I then outline a sequence of deductions that eliminate the apparent conflict between what the speaker says and the assumption of his cooperation.

\subsection{Recognition}

The general mechanism for the recognition of a conversationally relevant description follows the famit iar Gricean path. The hearer begins by assuming that the referring expression is only functionally relevant, and then gets into difficulties. An obvi ous strategy is illustrated by Example (3) above. At first glance it appears that the mayor violated the third maxim of manner ( ${ }^{\circ}$ Be brief"): he used a long and cumbersome description ("the city with the largeat Jewrish community"), although a much ahorter and functionally superior one is available ("New York"). However, a hearer can easily make sense of the mayor's behavior by assuming that the referring expression is not merely a tool for identification. That is, it must be conversationally relevant.

Another strategy for letting the hearer recognise a conversationally relevant description is illustrated by "Smith's murderer" (interpreted "attributively"). There, the assumption that the description is only functionally relevant would lead to an inexplicable violation of the second maxim of quality. It is obvions that no one knows yet who murdered Smith. Thus, if the description is only functionally relevant, the hearer would be pussled as to how the speaker could form an opinion about the sanity of a person whose identity is unknown to him.

\subsection{Asserted universality}

When a conversationally relevant description is used (or implied), the proposition which the speaker is trying to express lends itself to the Russellian analysis. Thus, if a speaker asserts a statement of the form

\section{The $D$ is $F$,}

and "The $D$ ' is a conversationally relevant description, then the proposition expessed by the speaker is this:

$$
5(\exists x)(D(x) \&(\forall y)(D(y) \rightarrow x=y) \& F(x)) .^{\perp}
$$

Note that (5) is equivalent to the conjunction of two propositions. The first one is the uniqueness condition:

$$
\text { 6 (Uniqueneas) }(\exists x)(D(x) \&(\forall y)(D(y) \rightarrow x=y)) \text {. }
$$

The second is a universal generalization:

$$
T \text { (Universality) }(\forall z)(D(z) \rightarrow F(z))
$$

Both the uniqueness and the universality conditions have to be satisfied if what the speaker means is to be true. But from this it does not follow that the speaker asserts these conditions. Both Strawson [1971] and following him Searle [1969, 157ff.] have argued in their criticism of Russell's theory of descriptions that the uniqueness condition, though presupposed, is not asserted. For example, when a speaker says that the Queen of England is ill, he does not assert that there is one and only one Queen

\footnotetext{
'Contextual information may be needed to augment the deacriptive content of "The $D$."
} 
of England. This, no doubt, is true of the uniqueness condition, but I think that when a conversationally relevant description is used, the universality condition is indeed asserted, or at least strongly implied. In a sense, what the speaker attempts to convey is that any object that is denoted by the description the $D^{-}$has the property $F$, and this is why it is so natural to insert "whoever he is" in the classical examples of attributive uses of definite descriptions. By saying 'Smith's murderer, whoever he is, is insane" the speaker obviously means that for any person, if that person is Smith's murderer, that person is insane, which has the exact same form as (7). Note that the convention for using definite descriptions to express universal statements already exists in the language ("The whale is a mammaP i.e., for any $x$, if $I$ is a whale, then $x$ is a mammal). Moreover, very frequently, when a conversationally relevant description is used, the speaker would maintain that the universality condition is true even if uniqueness fails. Suppose it turns out that not one but two culprits are responsible for Smith's sorry state. If our speaker asserted that Smith's murderer, whoever he is, is insane, he is very likely to say now that both are insane, rather than withdraw his judgment altogether. All in all, it seems to me very plausible to assume that when conversationally relevant descriptions are used, the universal claim is not only part of the truth conditions (together with uniqueness), but part of what is asserted as well.

\subsection{Justification}

A rational speaker who follows the Gricean maxims is expected, among other things, to obey the second maxim of quality. That is, he is expected to have "adequate evidence" for what he asserts. What counts as adequate evidence obvionsly depends on context: we have different standards for assertions in a scientific article and in a gossipy chat. Nevertheless in all verbal exchanges, a speaker is expected to be able to provide reasonable justification for what he says. He must be able to answer questions such as "how do you know?" "why do you think so?" and so on. If he cannot, the assumption about his cooperation cannot be maintained.

If a universal statement such as (7) is part of what the speaker asserts, he must be able, then, to justify it. The hearer may not know exactly what the speaker's evidence is for believing this generalisation but the hearer can reason about the type of evidence or justification that the speaker is expected to have. In particular, I want to draw a distinction between extensional and intensional justifications of universal statements. This distinction will help us see what sort of justification a speaker can offer for a statement such as (7) when a conversationally relevant description is used.

The distinction between extensional and intensional justification of universal statements is based on a familiar distinction in the philosophy of science between accidental and lawlike generalisations (See Walters 1967). Not all universal generalisations are scientific laws. For example, the following statement, although true, is not a law of nature:

8 All mountains on Earth are less than 30,000 feet high.

On the other hand, this next statement is:

\section{All basketballs are attracted to the center of Earth.}

What is the difference? Well, there are several, but two related ones are specifically relevant to us. First, the latter generalisation, but not the former, supports counterfactual statement. If a mountain on Earth were to be examined a billion years from now, would it still be less than 30,000 feet high? We don't know. Changes in the surface of the earth occur all the time, and Mount Everest needs a mere 972 additional feet to make (8) false. On the other hand, if a player were to make a jump shot a billion years from now the basketball would still find its way down to the ground. A law of nature does not lose its validity over time.

Second, there is a crucial difference in the manner in which statements (8) and (9) are justified. The generalisation about mountains on earth is supported by observation: all mountains on earth were measured and found to be less than 30,000 feet high. I do not know why this is so. As far as I am concerned this is just one more accidental fact about the world I live in. The generalization about basketballs, on the other hand, is derived from a more general principle that explains why things such as basketballs behave the way they do. Such a derivation is an essential part of an explanation of why (9) is true. It also contributes to the coherence of our experience: what science provides us with, among other things, is the reassuring knowledge that natural phenomena do not just happen to occur, but follow a general scheme that provides the basis for both explanation and prediction. Thus, our confidence in the truth of (9) is not merely the result of examining a large sample of basketballs. We also have a theory that explains why they do not just happen to come down whenever dropped, but, in a sense, must do so.

Given these two differences between accidental and lawlike statements, let extensional and intensional justifications of universal generalizations be defined as follows. An extensional justification of a 
generalisation such as "All A's are F" would rely on the fact that all, or most, or a good sample of the things with the property $A$ have been examined and were found to have property $F$. In such a case there would not be any attempt to explain why this is so, only a claim that as things stand, all A's do, in fact, have the property $\boldsymbol{F}$. An intensional justification of a universal generalisation, on the other hand, would attempt to show that anything with the property of being $A$ must have the property of being $F$, because of a more general principle or theory from which the generalisation can be derived. ${ }^{2}$

The distinction I have just described is obviously not restricted to science, nor am I interested in elncidating different scientific methods of corroboration. Rather, I want to apply this distinction to the kind of justification that a speaker is expected to have for what he says, in view of Grice's second maxim of quality. In a sense, what I am after is a "folk theory" of justification, not the foundation of knowledge. Thus, the extensional/intensional distinction between types of justification is indifferent to the question whether the evidence for a statement is good or bad, as an intensional justification can be either silly or brilliant. Moreover, the distinction applies to all sorts of judgments, not merely theoretical ones. The biggotted justification for holding stereotypic beliefs would presumably be extensional ("Look, I don't know why they are all such dirty cowards, but I have met enough of them to know that they are!"). On the other hand, when the notorious fundamentalist preacher Jimmy Swaggart states that all adulterers are sinners, he does not intend us to believe that he has examined all (most, enough) adulterers and found that they happen to be sinners. If someone who is not an adulterer now would become one, he would have to be a sinner as well, and the reason for that is simple. Within Swaggart's world view, adulterers must be sinners simply because the bible says so, and whatever the bible says is true. The same distinction applies to the most mundane generalisations that can appear in discourse. "All the nursery schools in our area are simply unacceptable" my friend tells me. I assume the justification for what he says is extensional (he has checked out each and every one), but then he adds: "...they are all Montessori schools," and an intensional justification is revealed.

Clearly, extensional and intensional justification are not mutually exclusive. Nor do they exhaust the types of justification one can use. Thus, the justification of the most fundamental principles of any theory (scientific or otherwise), although clearly not extensional, would not be intensional either, since

\footnotetext{
${ }^{2}$ Statistical correlations belong to the extengional realm. Causal explanation to the intensional one.
}

by definition they are not derivable from any other principles (they would still support counterfactuals, though). However, apart from such fundamental axioms, the justification of any universal generaliration, if it is not extensional, must be intensional

Now back to the nniversality condition that the opeaker asserts when he uses a conversationally relevant description. As mentioned already, the hearer may not know why the speaker believes the generalisation, but from the hearer's point of view it stands to reason that the speaker's justification is intensional, because of the uniqueness condition. If the uniqueness condition is presupposed, an extensional justification of the universal generalisation amounts to no more than this: there is evidence that the referent happens to have the property $F$. But if this were all that the speaker had in mind, it would be very misleading to give the impression that a universal generalisation was meant. To see why, consider a case in which an author tells you that all his books are published by Cambridge University Press. If later you are to find out that he has published only one book, you would surely be pussled, although as things are, his statement was technically true. In other words, if the uniqueness condition is presupposed, it makes little sense to assert a universal generalisation, unless the speaker believes that the generalisation must be true whether the uniqueness condition is true or not. Thus, if the speaker has intensional justification for what he says, the uniqueness condition no longer interferes with universality. If the author tells you that he has just signed a lifetime contract with Cambridge University Press, and therefore all his books must be published there, the fact that he has written only one book (so far) does not matter any more. In view of the contract, if he were to write others, they would be published by Cambridge.

For the speech act to be coherent, therefore, the speaker must have an intersional justification for (7). This is why frequently when a conversationally relevant description is used (for example, in the paradigmatically "attributive" uses of definite descriptions), it is natural to replace the auxiliary verb with an appropriately tensed occurrence of "must." For example,

10 The inventor of the sewing machine, whoever he or she was, $\frac{\text { was }}{\text { must have been }}$ very smart.

11 If my political analysis is correct, the. Democratic candidate in 1992 will $\frac{\text { be }}{\text { have to be }}$ a conservative.

12 The thief who stole your diamond ring,

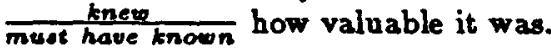


My hypothesis, therefore, is that conversationally relevant descriptions are used to assert universal generalisations for which the speaker has intensional justification. Therefore, when a speaker says "The $D$ is $F^{\prime \prime}$ and "The $D$ " is conversationally relevant, a first approximation of what is usually being implicated is this:

\section{Any $D$ must be $F$.}

When the modal verb is actually added, the speaker simply makes (part of) the implicature explicit.

\subsection{The meaning of "must"}

As it stands, the implicature expressed by (13) is hopelessly vague. The problem is with the modal verb "must." How is it to be interpreted? Compare, for example, the following uses:

14 (a) The bird must have entered through the attic.

(b) Whether I like it or not, I must pay my taxes.

(c) The Butcher of Lion must pay for his crimes.

If I do not pay my taxes, I will be punished. This is why I feel that I must do it. But if the bird did not enter through the attic, or if the Butcher of Lion does not pay for his crimes, neither bird nor beast will be punished as a result of that. Moreover, if the bird did not enter through the attic, the speaker uttering $14(a)$ would simply be wrong. But whether or not the Butcher of Lion ever pays for his crimes, the speaker uttering 14(c) would nevertheless be right. Thus, in each case, the intended interpretation of the modal verb is radically different.

Is the word "must" multiply ambiguous then? Not necessarily. As Angelika Kratser has argued [1977; 1979; 1981], the force of modal verbs such as "must" is relative to an implied contextual element. The examples in 14 are elliptical pronouncements whose full meaning can be given by the following:

15 (a) In view of what we know, the bird must have entered through the attic.

(b) In view of what the law is, I must pay my taxes, whether I like it or not.

(c) In view of our moral convictions, the Butcher of Lion must pay for his crimes.

The interpretation of "must" in each example is indeed different, but there is, Kratzer argues, a core of meaning which is common to all This core is specified as a function that can be precisely formulated within the framework of possible-world semantics. Schematically, Kratzer's suggestion is that the meaning of "must" is given by the function mustin-view-of, which accepts two arguments. One argument is the proposition within the scope of the modal verb (e.g., The bird came through the attic in 14(a)). Values for the other argument are phrases such as "what is known," "what the law is," "our moral convictions," etc. Thus, for example, sentence $15(\mathrm{a})$ is interpreted as

\section{Must-In-View-Of(What is known, The bird entered through he attic)}

The sentence is true in possible world $w$ just in case the proposition expressed by "The bird entered through the attic" logically follows from what we know in $w$ [Kratzer 1977, 346]. ${ }^{3}$

Kratser's suggestion can be used in the elucidation of the implicature conveyed by a conversationally relevant description. Let $f$ stand for phrases such as "what is known," "What the law is," etc. Applying Kratser's analysis to (13) we get

17 In view of $f$, any $D$ must be $F$.

or more accurately:

\section{Must-In-View-Of $(f$, any $D$ is $F)$.}

(18), then, is the implicature conveyed by a typical use of a conversationally relevant description. How "in view of $f^{\prime \prime}$ is to be interpreted is up to the hearer to find out, but we may assume that possible values for $f$ come from a list that is scanned by the hearer until a particular item on the list provides a satisfactory interpretation. Such a list may contain the following (see Kratzer 1981, 44-45, for possibleworld interpretation):

- Factual: In view of facts of such and such kinds... (including institutional facts such as what the law is).

\footnotetext{
"Phrases such as "what is known," "our moral convictions," "what the facts are," and so on are represented by Kratser a functions from possible worlds to sets of propositions. For example, "what is known" is represented as a function $f$ which assigns sets of propositions to possible worlds such that for each possible world $w, f(w)$ contains all the propositions that are known in that world. According to Kratzer's firat suggestion, for any function $f$ from worlds to sets of proponitions, and for every proposition $P$, "It must be the case that $P$ in view of $f^{\prime \prime}$ is true in $w$ just in case $f(w)$ entaila $P$. As Kratzer notes, this is only the first step in the elucidation of the meaning of modal verbe, and it works only when $f(w)$ is guaranteed to be consistent (as is indeed the case when $f$ is "what is known"). When $f(w)$ can be inconsistent (e.g., when $f$ is what the law in ), problems arise, which Kratzer solves using the concept of the set of all consistent subsets.
} 
- Epistemic: In view of what is known... (or alternatively, what is believed, assumed, hypothesised, and 80 on).

- Stereotypical: In view of the normal course of events...

- Deontic: In view of what is the right thing to do...

- Teleological: In view of our objectives ... (or alternatively, our wishes, our intentions, and so on).

While the list may turn out to be much longer, there is no reason to assume that it will be infinite.

The assumption that a conversationally relevant description is used to implicate a modal operator provides a formal reason why in paradigmatically attributive uses, if nothing fits the description, the speech act as a whole must fail. If (18) is part of what the speaker means in these cases, the description is within the scope of a modal operator, hence, within an intensional context in which substitntion is not guaranteed to be a valid form of inference. Suppose that Ralph asserts that in view of what we know about the normal human propensity for violence, Smith's murderer, whoever he is, must be insane; and suppose Ralph thinks that Smith's murderer is Jane's uncle. Substituting "Jane's uncle" for "Smith's murderer" yields the wrong result: it is not the case that in view of what we know about the normal humas propensity for violence, Jane's uncle, whoever he is, must be insane. Since in general substitution is not allowed in intensional contexts, when the description fails (i.e., no one murdered Smith), Ralph's speech act must fail too. The fact that he may know quite well who he thought the culprit was does not matter.

By way of summary, here are the steps that a hearer might go through in calculating the implicature that is typically intended when a conversationally relevant description is used:

1. Recognising a conversationally relevant description

2. Identifying the universal generalixation

3. Postulating an intensional justification

4. Locating an appropriate set of propositions relative to which the modal operator is interpreted

Of course, this mechanism is much more flexible than I make it out to be, and a speaker can use it to satisfy various other goals. For example, a definite description can be used to provide information [Appelt 1985], or to highlight shared knowledge, or simply to avoid mechanical repetition of a proper name. The following quotation illustrates how a conversationally relevant description can achieve all these goals simultaneously:
19 In the Democratic primaries, Mr. Jackson, who is considered a long shot for the Vice-Presidential nomination, received more than seven million votes. The f6-year-old Chieago elergyman has not said whether he wants the second spot on the Democratic ticket... (New York Times, June 28, 1988)

Since the name "Jackson" is already available as the best functionally relevant referring expression, it should be obvious to the reader that the description "the 46-year-old Chicago clergyman" is conversationally relevant. But if the reader were to go through the steps outlined above, he would reach a dead end. There is nothing in view of which it must be the case that any $\mathbf{4 6}$ year old Chicago clergyman has not said whether he wants the second spot on the democratic ticket. Thus, the implicature that usually accompanies a conversationally relevant description is ruled out. Nor is there an obvious implicit description that is used to convey a similar implicature. The reader is then forced to search for other explanations, and one obvious possibility is that the author wants to inform the reader (or remind him) that Jackson is a 46 year old clergyman from Chicago.

\section{Non-assertives}

So far I have assumed that the conversationally relevant description is used within the context of an assertion, and I have relied, in my derivation of the implicature, on the fact that in assertions the speaker is expected to have adequate evidence for what he says. In other speech acts, however, evidence and justification play a completely different role, if any. For example, a speaker who asks a question is not expected to have "evidence" for it. Still, the use of conversationally relevant descriptions is clearly not restricted to assertions. Consider the following:

20 [After the verdict is pronounced, the Mayor to the District Attorney] Congratulations on nailing the most fearsome criminal in recent history.

21 (While the serving plate is passed around, a guest to the host] I am not very hungry. Could I have the smallest steak please?

22 A young cop to his superior, as the chase begins]

One thing I can promise you: I will not let Smith's murderer get away!

A detailed description of how my account can be extended to cover these cases would take us too far 
afield. In general, however, the same analysis can apply to non-assertions such as the above as well. Coherence is no less important in discourse containing requests, warnings, promises, etc. than in one containing assertives. The hearer must understand the reasons why a congratulation, a request, or a promise are being performed, and the role of conversationally relevant descriptions in such speech acts would be similar to their roles in assertives, with similar implicatures. As rough approximations, the implicatures involved in the three examples above are expressed by the following statements, respectively:

- In view of the danger that criminals pose to society, nailing the most fearsome criminal in recent history is an act that must be congratulated.

- In view of my wish to stay both slim and polite, I must have the smallest steak.

- In view of my moral convictions, I should try my best to bring Smith's murderer to justice.

\section{Indefinite descriptions}

In this paper I take referring expressions to be uses of noun phrases that are intended to indicate that a particular object is being talked about. Hence, indefinite descriptions can obviously serve as referring expressions, and the distinction between functional and conversational relevance should apply to them as well. Usually, a use of an indefinite description as a referring expression signals to the hearer that the identity of the referent is not important (e.g., " $A$ policeman gave me a speeding ticket"). Some uses of indefinite descriptions, however, are cleariy made with the intention that the hearer identify whom the speaker has in mind. For example,

\section{A person $I$ know did not take out the} garbage as be had promised...

Here, identification is obviously required, but it does not matter at all how the referent is identified. The indefinite description is, therefore, only functionally relevant. In contrast, consider the following

24 A cardiovascuclar specialist told me that I exercise too much.

Although the identity of the physician is not important, the fact that he is a cardiovascular specialist surely is. The indefinite description is, therefore, conversationally relevant.

Deborah Dahl discusses interesting cases in which an indefinite description is both specific (i.e., used with the intention that the hearer know the identity of the referent) and attributive (that is, conversationally relevant). Here is one of her examples:
25 Dr. Smith told me that exercise helps. Since I heard it from a doctor, I'm inclined to believe it [Dahl 1984].

Clearly, an accurate interpretation of "a doctor" wonld connect the referent with Dr. Smith. At the same time, the use of the indefinite description highlights a property of Smith which is conversationally relevant. Note that the indefinite description is used to implicate a nniversal generalisation, namely, that in view of what doctors know, any doctor who gives you an advice, should (other things being equal) be listened to. This is very similar in structure to the implicature that is typically associated with conversationally relevant definite descriptions.

As is the case with definite descriptions, such uses of indefinite descriptions can accomplish other purposes besides (or instead of) implicating a universal generalisation. For example,

26 In fact, the Dewey-Truman matchup illustrates the point. Mr. Truman was thought to be a weak leader who could not carry out his strong predecessor's program. His election prospects were bleak. The pundits were against him and a highly successjul Northeastern Governor was poised to sweep into the White House. (New York Times, May 26, 1988)

The calculation of the implicature conveyed by the indefinite description is left as an exercise for the reader.

\section{REFERENCES}

Allen, J. F. 1978. Recognizing Intention in Dialogue. Ph.D. diss., University of Toronto.

Allen, J. F. and C. R. Perrault. 1978. Participating in dialogues: understanding via plan deduction. In Proceedings, Canadian Society for Computational Studies of Intelligence.

Allen, J. F. and C. R. Perrault. 1980. Analyzing intention in dialogues. Artificial Intelligence, 15(3):143-178.

Appelt, D. E. 1985. Planning English Sentences. Cambridge Univ. Press, Cambridge.

Dahl, Deborah A. 1984. Recognizing sepcific attributes. presented at the 59th Annual Meeting of the Linguistic Society of America. Baltimore.

\footnotetext{
In this op-ed, piece the author argues that polls showing Michael Dukakis leading George Bush in the race for the presidency do not mean much. Note that in May 1988, Dukakis is the Governor of Massachusetts, a Northeastern state.
} 
Gross, B. J. and C. L. Sidner. 1986. Attention, intentions, and the structure of discourse. Computational Linguistics, 12(3):175-204.

Kratser, A. 1977. What 'must' and 'can' must and can mean. Linguistics and Philosophy, 1(1):337-335.

Kratser, A. 1979. Conditional necessity and possibility. In U.Ëgli R.B̈zunerle and A.V̄on Stechow, editors, Semantics for Different Points of View, pp. 117-147, Springer-Verlag, Berlin.

Kratser, A. 1981. The notional category of modality. In H. J. Eikmeyer and H. Rieser, editors, Words, Worlds, and Conterts: New Approaches in Word Semantics, Pp. 38-74, Walter de Gruyter, Berlin.

Kronfeld, A. 1986. Donnellan's distinction and a computational model of reference. In Proceedings of the 2fth Annual Meeting, pp. 186-191, Association for Computational Linguistics.

Kronfeld, A. 1990. Reference and Computation: an Essay in Applied Philosophy of Language. Cambridge Univ. Press, Cambridge.

Perrault, C. R., J. F. Allen, and P. R. Cohen. 1978. Speech acts as a basis for understanding dialogue coherence. In TINLAP-2, pp. 125132, University of Dlinois, Urbana-Champaign.

Searle, J. R. 1969. Speech Acts: An Essay in the Philosophy of Language. Cambridge Univ. Press, Cambridge.

Sidner, C. L. 1983. What the speaker means: the recognition of speakers' plans in discourse. International Journal of Computers and Mathematics, 9(1):71-82.

Sidner, C. L. 1985. Plan parsing for intended response recognition in discourse. Computational Intelligence, 1(1):1-10.

Strawson, P. F. 1971. On referring. In J.F Rosenberg and C. Travis, editors, Reading in the Philosophy of Langrage, Prentice Hall, Englewood, N. J.

Walters, R. S. 1967. The Encyclopedia of Philosophy, pp. 410-414. Volume 4, Macmillan, New York. s.v. "laws of science and lawlike statements". 